\title{
openheart A propensity matched comparison of return to work and quality of life after stenting or coronary artery bypass surgery
}

\author{
Annette M Maznyczka, ${ }^{1,2}$ James $\mathrm{P}$ Howard, ${ }^{3}$ Amerjeet S Banning, ${ }^{4}$ \\ Anthony $\mathrm{H}$ Gershlick ${ }^{4}$
}

To cite: Maznyczka AM, Howard JP, Banning AS, et al. A propensity matched comparison of return to work and quality of life after stenting or coronary artery bypass surgery. Open Heart 2016;3:e000322. doi:10.1136/openhrt-2015000322

Received 28 July 2015 Accepted 9 December 2015

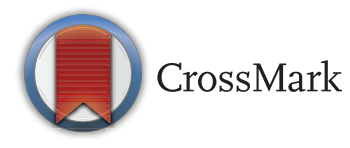

${ }^{1}$ Kings College London, London, UK

${ }^{2}$ Department of Medical Sciences, University College London, London, UK ${ }^{3}$ International Centre for Circulatory Health, National Heart and Lung Institute, London, UK

${ }^{4}$ Department of

Cardiovascular Sciences,

University of Leicester and NIHR Leicester

Cardiovascular Biomedical Research Unit, University Hospitals of Leicester NHS Trust, Glenfield Hospital, Leicester, UK

\section{Correspondence to} Dr Annette M Maznyczka; annette.maznyczka.13@ucl. ac.uk

\section{ABSTRACT}

Objectives: We sought to determine (1) return to work (RTW) rates, (2) long-term employment (>12 months postprocedure), (3) time taken to RTW, and (4) quality of life (QoL), in patients treated with percutaneous coronary intervention (PCl) or coronary artery bypass grafting (CABG).

Methods: Questionnaires regarding RTW were sent to $689 \mathrm{PCl}$ and $169 \mathrm{CABG}$ patients who underwent $\mathrm{PCl}$ or CABG at University Hospitals of Leicester Trust, UK, from May 2012 to May 2013. QoL was also measured using the European QoL 5-dimensions questionnaire (EQ-5D). Responses from patients employed preprocedure were analysed using multivariate logistic regression. Propensity score-matching was further used to compare similar patient populations receiving $\mathrm{PCl}$ or CABG.

Results: The response rate was $38 \%(235 \mathrm{PCl}$ and 88 CABG patients). 241 respondents (75\%) were employed preprocedure. Of these $162(93 \%) \mathrm{PCl}$ and $51(77 \%)$ CABG patients returned to work, whereas $147(85 \%)$ $\mathrm{PCl}$ and $41(62 \%)$ CABG patients were still employed at $>12$ months postprocedure. After propensity analysis, there was no significant difference between $\mathrm{PCl}$ and CABG patients in RTW, long-term employment, nor QoL. The median time taken to RTW was 6 weeks after $P C l$ and 13 weeks after CABG $(p=0.001)$. The effect remained significant after multivariate analysis ( $p=0.001)$ and propensity analysis $(p=0.001)$.

Conclusions: In this first propensity score-matched study comparing RTW and QoL after PCI or CABG strict propensity matching indicates that RTW or QoL, is similar for PCI or CABG, albeit the number of matched pairs was small. There are differences, however, in delay in RTW.

\section{INTRODUCTION}

Coronary heart disease can cause premature disability, resulting in socioeconomic issues. ${ }^{1}$ A better understanding of return to work (RTW) and quality of life (QoL) after percutaneous coronary intervention (PCI) and coronary artery bypass grafting (CABG) may

\section{KEY QUESTIONS}

What is already known about this subject?

- Previous studies have reported earlier return to work (RTW), but generally similar long-term employment, after percutaneous coronary intervention (PCl) compared with coronary artery bypass grafting (CABG). While some studies have reported no difference in quality of life (QoL) after $\mathrm{PCl}$ or CABG, others have reported better long-term QoL after CABG. However, previous studies did not use propensity matching to strengthen causal inferences, and most were prior to the current era of drug eluting stents and short post-PCI in-patient stay.

What does this study add?

- This is the first propensity score-matched study comparing RTW and QoL after either $\mathrm{PCI}$ or CABG surgery in the contemporary era. Contemporary $\mathrm{PCl}$ when compared to $\mathrm{CABG}$ surgery predicts earlier RTW. However, after propensity analysis there was no difference between contemporary PCI or CABG surgery in RTW, long-term employment or QoL. The propensity matching which was strict may have limited the comparisons. The results suggest younger age, not having diabetes mellitus, good ejection fraction and not being self-employed are the strongest predictors of RTW.

How might this impact on clinical practice?

- RTW and QoL concerns should not drive decision-making regarding selection of $\mathrm{PCl}$ or $C A B G$ surgery for patients requiring revascularisation. However, from a patient perspective knowing that time taken to RTW is longer after CABG surgery than after PCl may be an important issue to be aware of.

help inform patients better, and could provide metrics for patients and physicians to understand longer term social outcomes.

Widely variable RTW rates have been reported in previous studies, ranging from 
$17 \%$ to $90 \%$ after CABG and $56 \%$ to $98 \%$ after PCI with angioplasty, using bare metal stents (BMS) or first generation drug eluting stents (DES). ${ }^{2}$ Factors reported to influence RTW and/or QoL after PCI or CABG surgery include: low socioeconomic status, ${ }^{3}$ unmarried status, ${ }^{4}$ job dis-satisfaction, ${ }^{5}$ pretreatment employment status, ${ }^{6}$ age, ${ }^{48} 8$ preprocedural angina ${ }^{9}$ and left ventricular function. ${ }^{7}$ It has been suggested that the strongest predictors of RTW after PCI are: age, sociopsychological and occupational factors. ${ }^{4}$

The limitations of previous studies were their being set in the previous balloon angioplasty or BMS era and are of historical value only. Furthermore, while some beliefs may be intuitive, previous observational studies of RTW did not use propensity score-matching to minimise selection bias and strengthen causal inferences.

The purpose of this study was to test for any differences in RTW and QoL between contemporary PCI and $\mathrm{CABG}$, in a propensity score-matched population. Specific objectives were to describe: (1) RTW rates, (2) employment at $>12$ months postprocedure, (3) time taken to RTW, (4) QoL and (5) determine which factors influence RTW and QoL, after either PCI or CABG.

\section{METHODS}

\section{Participants}

Patients who underwent PCI or CABG surgery, at University Hospitals of Leicester Trust, were identified from a prospectively collected database. To allow for at least 1 year of follow-up, the time period chosen was 1 May 2012 to 1 May 2013. Of the 2323 patients identified, 1465 patients were excluded for the following reasons: age $>65$ years $(n=1196,51.5 \%)$, death $(n=65,2.8 \%)$, concomitant valve surgery $(\mathrm{n}=164,7.1 \%)$, unsuccessful PCI $(n=22,0.9 \%)$, or non-UK, or prison address $(n=18$, $0.8 \%$ ). Thus 858 patients were deemed eligible for inclusion in the study (criteria: age $\leq 65$ years (on the basis of probability of not being age-retired), CABG surgery, or PCI procedure for acute or stable indication). Questionnaires were sent by postal mail, in August 2014, to 169 patients who had undergone CABG surgery and 689 patients treated with PCI. Data return was supplemented with that from the hospital database, to determine left ventricular ejection fraction (EF) and body mass index results for each participant. Power calculations, derived from the results of previously published studies, were deemed unlikely to be meaningful, due to the wide range of RTW rates in previous publications.

\section{RTW assessments}

RTW patterns were assessed using a questionnaire designed in three sections (figure 1). The first focused on demographic factors and questions related to the procedure; the second section on preprocedure work status and the third section focused on postprocedure work status. Questionnaires were analysed anonymous to procedure to minimise bias, by allocating a number to each questionnaire, corresponding to the patient's hospital number and then entering these into a separate database. Long-term employment was defined as 'still employed $>12$ months postprocedure'. ${ }^{10}$

\section{QoL assessments}

QoL was assessed using the standardised European QoL 5-dimensions questionnaire (EQ-5D). ${ }^{11}$ The 5 item EQ-5D QoL questionnaire was used, rather than the 19 item Seattle Angina Questionnaire, or the 36 item SF-36 questionnaire, to reduce respondent time burden and since EQ-5D questionnaire results can be easily quantified to detect treatment-related differences.

The EQ-5D questionnaire comprised two sections. The first part contained five questions reflecting five health dimensions: mobility, self-care, usual activity, pain or discomfort and anxiety or depression. Participants were asked to respond to these questions by marking the most appropriate of three possible response levels (1: no problems; 2: some problems; or 3: extreme problems). The second part was the visual analogue scale, that is, a vertical scale that ranged from 0 (worst imaginable health status) to 100 (best imaginable health status). Participants were asked to assess their health state by drawing a line to the appropriate point on the scale.

\section{Statistical analysis}

Baseline characteristics and reported summary statistics are presented as number and percentages for categorical data, and for continuous data as mean $\pm \mathrm{SD}$, or median with range. Time to RTW is presented as median with range in weeks. Statistical comparison between groups was performed using $\chi^{2}$ test, or Fisher's exact tests where appropriate for categorical data and $t$ test for continuous data. The Mann-Whitney test was performed for comparison of non-parametric data. $p$ value $<0.05$ was considered to represent statistical significance.

Responses from patients employed preprocedure were analysed using multivariate logistic regression. To allow for potential confounding factors between treatments that could influence RTW and QoL, propensity score matching was performed. The following factors were included in the propensity score model; age, gender, procedural urgency, $\mathrm{EF}<30 \%$ and preprocedural job characteristics (self-employed, physical job, stressful job, emotionally demanding job and job with much responsibility). Owing to the significant differences in baseline characteristics between the PCI and CABG groups, calliper matching was used to ensure that each matched variable was within $1 / 4$ SD of the matched partner's. The purpose of the propensity score-matching strategy was to reduce confounding effects of these variables, and strengthen causal inferences. Statistics were performed using R V.3.1.2, and propensity score analysis was performed using the 'MatchIt' ${ }^{\text {'2 }}$ and 'Zelig'"13 packages. Patients with missing values were excluded from the univariate, multivariate and propensity analyses. 

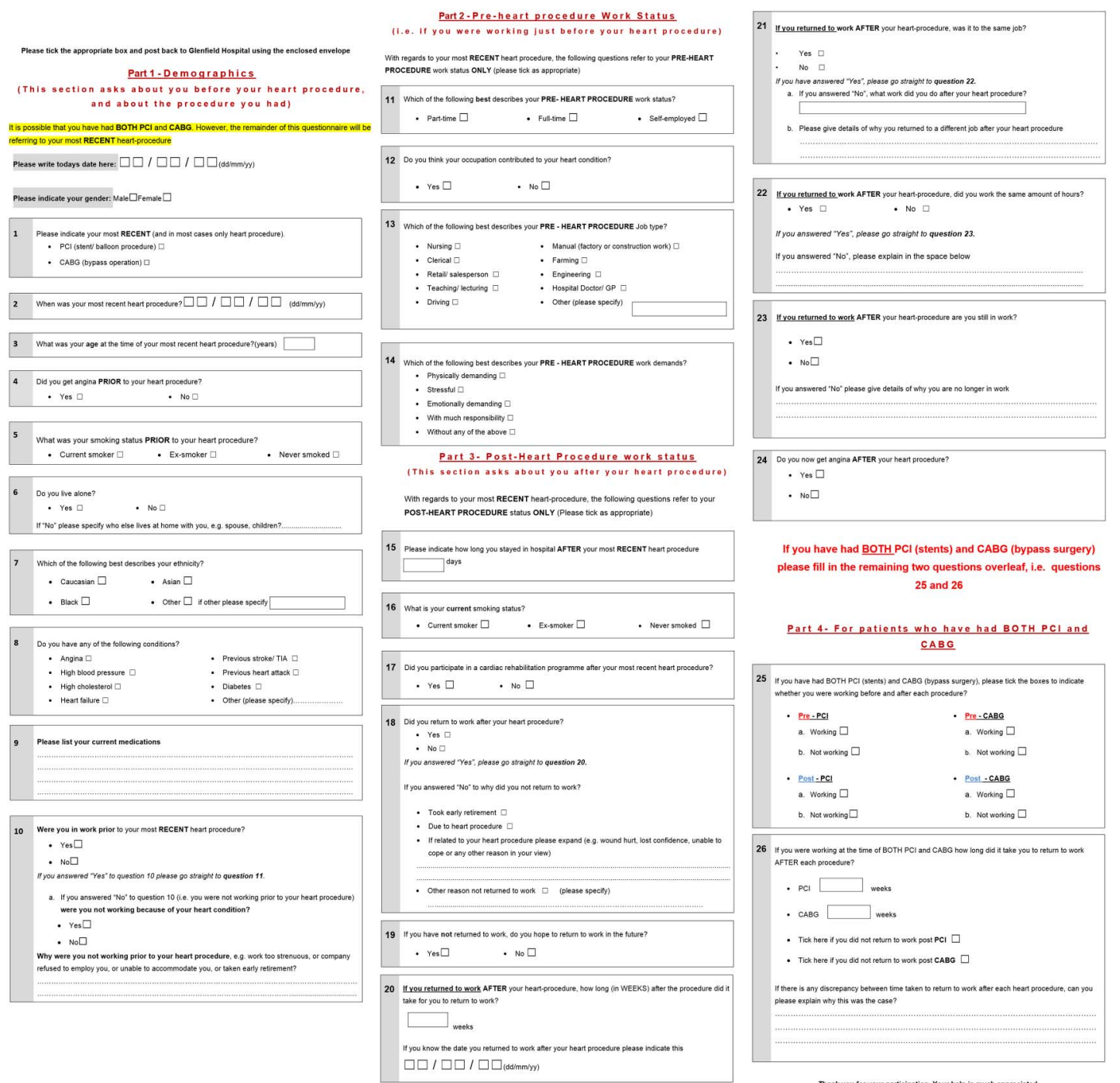

If you have had BOTH PCI (stents) and CABG (bypass surgery) please fill in the remaining two questions overleaf, i.e. questions

Part 4. For patients who have had BOTH PCl and $\underline{\mathrm{CABG}}$

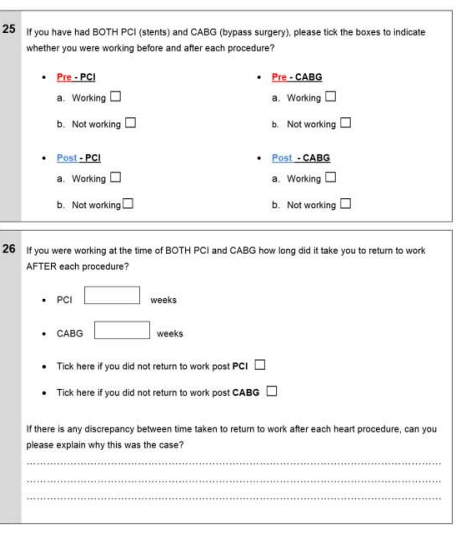

Figure 1 Return to work (RTW) questionnaire.

\section{RESULTS}

\section{Participants}

Out of 858 participants eligible for inclusion in the study, questionnaires were returned by 323 participants (235 PCI patients and 88 CABG patients), a response rate of $38 \%$. Regardless of this response rate the results are generalisable, since there were no formal power calculations and selection bias of returns was unlikely. The flow of participants through the study is illustrated in figure 2. The overall median time interval from undergoing revascularisation to completing the questionnaire was 21 months (range: 12-27 months).

\section{Descriptive data}

The demographics and procedural characteristics for respondents who were employed preprocedure $(n=241)$ and either did RTW $(n=213)$ or did not RTW $(n=28)$ postprocedure are shown in table 1 . The percentages in table 1 represent the proportion of respondents employed preprocedure who did not RTW (column 2), or did RTW (column 3), with that particular characteristic. The demographics and procedural characteristics for respondents who were employed preprocedure and either employed, or unemployed, $>12$ months postprocedure are shown in table 2. The percentages in table 2 represent the proportion of respondents employed preprocedure who were either unemployed >12 months postprocedure (column 2), or still employed $>12$ months postprocedure (column 3), with that particular characteristic.

Of respondents employed preprocedure data were missing for the following variables: living alone $(n=2)$, body mass index $(n=5)$, smoking status postprocedure $(n=1)$, EF $(n=38)$, preprocedure job type $(n=3)$, participation in cardiac rehabilitation $(n=2)$ and preprocedure job physically demanding $(n=3)$.

Of respondents employed preprocedure data were missing for the following outcomes: still employed $>12$ months postprocedure $(\mathrm{n}=2)$ and time taken to RTW (n=32). Furthermore, 37 respondents did not answer any questions in the QoL questionnaire, despite filling in the RTW questionnaire, thus data were missing from these 37 respondents on the QoL outcomes. 


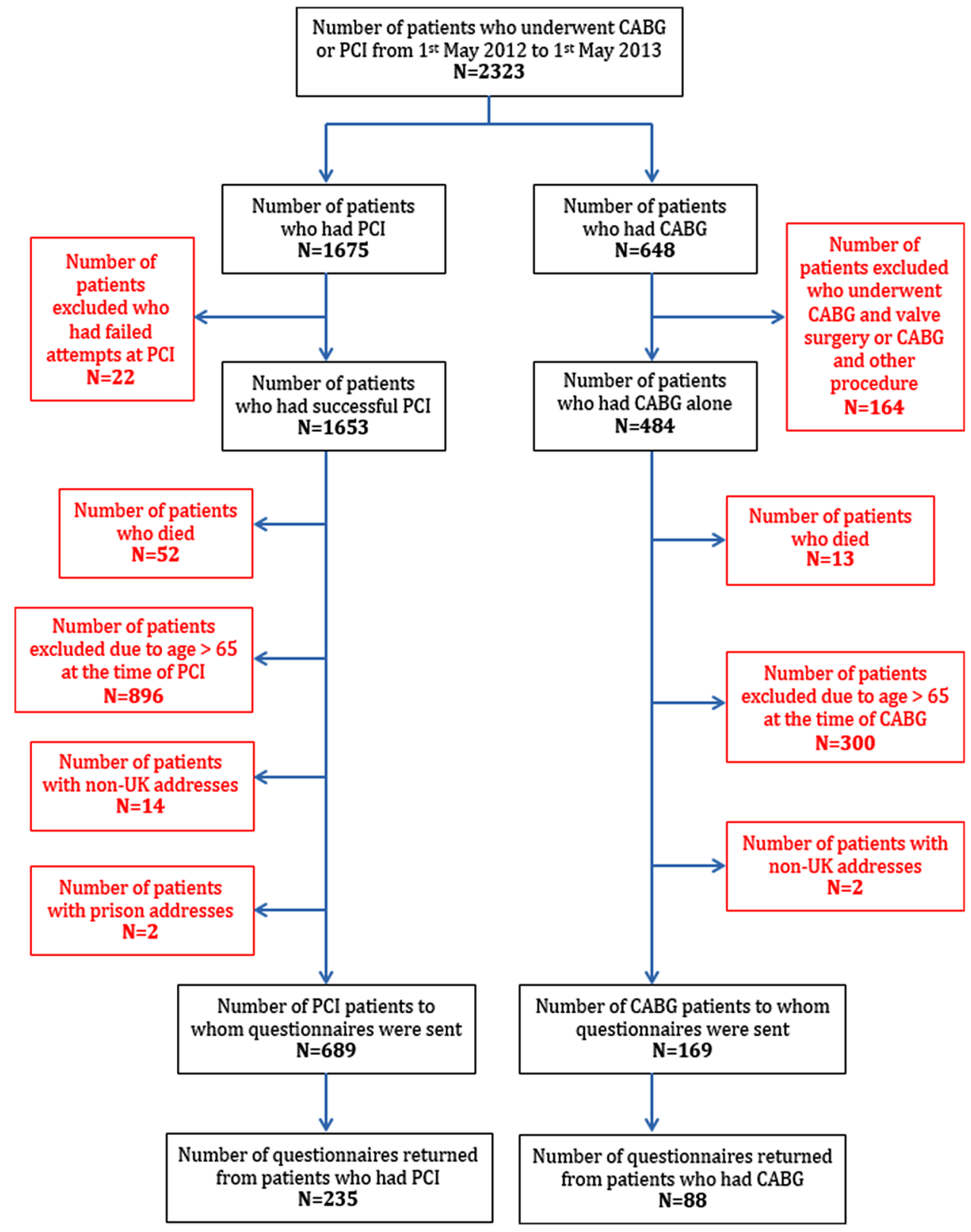

Figure 2 Flow of participants through the study.

\section{Outcome data}

Return to work

Overall 82 of all 323 respondents (25\%) were unemployed preprocedure. Ninety six of 323 respondents $(30 \%)$ were unemployed postprocedure. Only $14 \%(n=13)$ of respondents unemployed postprocedure wanted to RTW in the future. Early retirement was the most frequent reason for unemployment postprocedure $(57 \%)$ (figure 3). Other self-reported reasons for unemployment postprocedure were: (1) the 'underlying heart condition', or the revascularisation procedure $(19 \%)$, (2) other ill-health $(17 \%)$, (3) redundancy $(2 \%)$, (4) being a housewife (4\%) and (5) caring for a relative $(1 \%)$.

Two hundred and forty-one respondents $(75 \%)$ were employed preprocedure. Of these $88 \%$ returned to work. Overall $31 \% \quad(n=74)$ of respondents who were employed preprocedure thought their job contributed to their heart condition.

Factors that were significantly associated with RTW after multivariate analysis (MVA) of the unmatched cohort were younger age $(\mathrm{p}=0.001)$, not having diabetes mellitus (DM) $(\mathrm{p}=0.011), \mathrm{EF}>30 \%(\mathrm{p}=0.035)$ and not being self-employed $(\mathrm{p}=0.001)$.

Out of respondents who underwent PCI and were employed preprocedure $162(93 \%)$ returned to work and $13(7 \%)$ did not $(p=0.002)$. Out of respondents who underwent $\mathrm{CABG}$ and were employed preprocedure, 51 $(77 \%)$ returned to work and $15(23 \%)$ did not ( $\mathrm{p}=0.002$ ), suggesting patients are more likely to RTW after PCI compared to CABG. Out of the respondents who were employed preprocedure and returned to work, 
Table 1 Demographics for respondents who were employed preprocedure, and either did or did not return to work postprocedure

\begin{tabular}{|c|c|c|c|}
\hline Characteristic & $\begin{array}{l}\text { Employed preprocedure } \\
\text { and did not return to work } \\
(\mathrm{N}=28)\end{array}$ & $\begin{array}{l}\text { Employed pre procedure } \\
\text { and returned to work } \\
(\mathrm{N}=213)\end{array}$ & $\begin{array}{l}p \text { Value from } \\
\text { univariate } \\
\text { analysis }\end{array}$ \\
\hline Male, N (\%) & $21(75)$ & $192(90)$ & 0.024 \\
\hline Age at procedure $($ mean $\pm S D)$ & $61.5(51-65)$ & $57(34-65)$ & 0.0003 \\
\hline CABG, N (\%) & $15(54)$ & $51(24)$ & 0.002 \\
\hline $\mathrm{PCl}, \mathrm{N}(\%)$ & $13(46)$ & $162(76)$ & 0.002 \\
\hline Acute procedure, $\mathrm{N}(\%)$ & $19(68)$ & $129(61)$ & 0.457 \\
\hline DM, N (\%) & $13(46)$ & $39(18)$ & 0.001 \\
\hline $\mathrm{BMI}(\operatorname{mean} \pm \mathrm{SD})$ & $29 \pm 4$ & $\begin{array}{l}28 \pm 5 \\
\text { (5 missing) }\end{array}$ & 0.141 \\
\hline MI, N (\%) & $20(71)$ & $115(54)$ & 0.086 \\
\hline Smoking post procedure, $\mathrm{N}(\%)$ & $\begin{array}{l}1 \text { (4) } \\
\text { (1 missing) }\end{array}$ & $21(10)$ & 0.317 \\
\hline$E F<30 \%, N(\%)$ & $\begin{array}{l}3 \text { (11) } \\
\text { (1 missing) }\end{array}$ & $\begin{array}{l}5 \text { (3) } \\
\text { (37 missing) }\end{array}$ & 0.005 \\
\hline Lives alone, $\mathrm{N}(\%)$ & $5(18)$ & $\begin{array}{l}22(10) \\
(2 \text { missing) }\end{array}$ & 0.249 \\
\hline Self-employed, N (\%) & $4(14)$ & $\begin{array}{l}44 \text { (21) } \\
\text { (3 missing) }\end{array}$ & 0.00004 \\
\hline Preprocedure job physically demanding, $\mathrm{N}(\%)$ & $13(46)$ & $\begin{array}{l}80 \text { (38) } \\
(3 \text { missing) }\end{array}$ & 0.397 \\
\hline Preprocedure job stressful, N (\%) & $15(54)$ & $\begin{array}{l}112 \text { (53) } \\
\text { (3 missing) }\end{array}$ & 0.981 \\
\hline Preprocedure job emotionally demanding, $\mathrm{N}(\%)$ & $4(14)$ & $\begin{array}{l}45 \text { (21) } \\
\text { (3 missing) }\end{array}$ & 0.384 \\
\hline Preprocedure job with much responsibility, N (\%) & $9(32)$ & $\begin{array}{l}87 \text { (41) } \\
\text { (2 missing) }\end{array}$ & 0.359 \\
\hline Cardiac rehabilitation $(\mathrm{N}, \%)$ & $17(61)$ & $\begin{array}{l}136(64) \\
(2 \text { missing) }\end{array}$ & 0.699 \\
\hline
\end{tabular}

$51(24 \%)$ underwent CABG and $162(76 \%)$ underwent PCI. However, type of revascularisation procedure was not associated with RTW after MVA ( $\mathrm{p}=0.402)$.

After using caliper-matched $(1 / 4 \mathrm{SD})$ propensity scores to select a balanced cohort of 32 pairs, there was no significant difference between PCI and CABG patients in RTW ( $\mathrm{p}=1.000)$ (table 3).

\section{Long-term employment}

Overall 21\% ( $\mathrm{n}=51)$ of respondents, who were employed preprocedure, were not working $>12$ months postprocedure. After MVA younger age $(p=0.000001)$ and not having DM $(p=0.018)$ remained significantly associated with long-term employment.

Of respondents who underwent PCI and were employed preprocedure $147(85 \%)$ were still employed $>12$ months postprocedure, $(p=0.0002)$. Out of respondents who underwent $\mathrm{CABG}$ and were employed preprocedure 41 (62\%) were still employed $>12$ months postprocedure, whereas $25(38 \%)$ were not $(\mathrm{p}=0.0002)$. Out of the respondents who were still employed $>12$ months postprocedure, $147(78 \%)$ were treated with PCI and 41 (22\%) underwent CABG. However, after MVA of the unmatched cohort there was no significant difference between PCI and $\mathrm{CABG}$ in long-term employment $(\mathrm{p}=0.165)$.

Likewise, after using propensity scores to select a balanced cohort of 32 pairs, there was no significant difference between PCI and CABG in long-term employment $(\mathrm{p}=0.756)$ (table 3).

\section{Time taken to RTW}

The median time taken to RTW was 6 weeks (range: 0.14-78) after PCI and 13 weeks (range: 2-52) after CABG $(p=0.001)$. The effect remained significant on MVA $(\mathrm{p}=0.001)$ and after propensity analysis $(\mathrm{p}=0.001)$ (table 3).

\section{Quality of life}

There were no significant differences in self-reported health state scores between PCI and CABG procedures at median follow-up (table 4).

MVA of the unmatched cohort revealed that factors significantly associated with worse self-reported health state scores were living alone $(\mathrm{p}=0.041), \mathrm{DM}(\mathrm{p}=0.003)$, 
Table 2 Demographics for respondents who were employed preprocedure, and were either still working $>12$ months postprocedure, or unemployed $>12$ months postprocedure

\begin{tabular}{|c|c|c|c|}
\hline Characteristic & $\begin{array}{l}\text { Employed preprocedure } \\
\text { and unemployed } \\
>12 \text { months postprocedure } \\
(\mathrm{N}=51)\end{array}$ & $\begin{array}{l}\text { Employed preprocedure } \\
\text { and still working } \\
>12 \text { months postprocedure } \\
(\mathrm{N}=188)\end{array}$ & $\begin{array}{l}p \text { Value from } \\
\text { univariate } \\
\text { analysis }\end{array}$ \\
\hline Male, N (\%) & $42(82)$ & $169(90)$ & 0.143 \\
\hline Age at procedure (median+range) & $62(42-65)$ & $56(34-65)$ & 0.0000001 \\
\hline CABG, N (\%) & $25(49)$ & $41(22)$ & 0.0002 \\
\hline $\mathrm{PCl}, \mathrm{N}(\%)$ & $26(51)$ & $147(78)$ & 0.0002 \\
\hline Acute procedure, $\mathrm{N}(\%)$ & $33(65)$ & $113(60)$ & 0.550 \\
\hline DM, N (\%) & $18(35)$ & $34(18)$ & 0.010 \\
\hline $\mathrm{BMI}(\operatorname{mean} \pm \mathrm{SD})$ & $29 \pm 5$ & $\begin{array}{l}28 \pm 5 \\
\text { (5 missing) }\end{array}$ & 0.085 \\
\hline MI, N (\%) & $28(55)$ & $105(56)$ & 0.904 \\
\hline Smoking postprocedure, N (\%) & $\begin{array}{l}4 \text { (8) } \\
\text { (1 missing) }\end{array}$ & $18(10)$ & 0.733 \\
\hline$E F<30 \%, N(\%)$ & $\begin{array}{l}3(7) \\
(5 \text { missing })\end{array}$ & $\begin{array}{l}5 \text { (3) } \\
\text { (33 missing) }\end{array}$ & 0.026 \\
\hline Lives alone, $\mathrm{N}(\%)$ & $9(18)$ & $\begin{array}{l}17 \text { (9) } \\
\text { (2 missing) }\end{array}$ & 0.091 \\
\hline Self-employed, N (\%) & $8(16)$ & $\begin{array}{l}39 \text { (21) } \\
\text { (3 missing) }\end{array}$ & 0.018 \\
\hline $\begin{array}{l}\text { Preprocedure job physically demanding, } \\
\mathrm{N}(\%)\end{array}$ & $22(43)$ & $\begin{array}{l}70 \text { (38) } \\
\text { (3 missing) }\end{array}$ & 0.493 \\
\hline Preprocedure job stressful, N (\%) & $30(59)$ & $\begin{array}{l}96(52) \\
\text { (3 missing) }\end{array}$ & 0.380 \\
\hline $\begin{array}{l}\text { Preprocedure job emotionally demanding, } \\
\mathrm{N}(\%)\end{array}$ & $9(18)$ & $\begin{array}{l}40 \text { (22) } \\
\text { (3 missing) }\end{array}$ & 0.536 \\
\hline $\begin{array}{l}\text { Preprocedure job with much responsibility, } \\
\mathrm{N}(\%)\end{array}$ & $15(29)$ & $\begin{array}{l}81(43) \\
(2 \text { missing) }\end{array}$ & 0.071 \\
\hline Cardiac rehabilitation, $\mathrm{N}(\%)$ & $30(59)$ & $\begin{array}{l}120(65) \\
(2 \text { missing) }\end{array}$ & 0.815 \\
\hline
\end{tabular}

and having a physical job $(\mathrm{p}=0.005)$. After MVA of the unmatched cohort: Caucasians had fewer pain/discomfort problems $(p=0.015)$; diabetics had more problems with mobility $(\mathrm{p}=0.047)$ and self-care $(\mathrm{p}=0.021)$; living

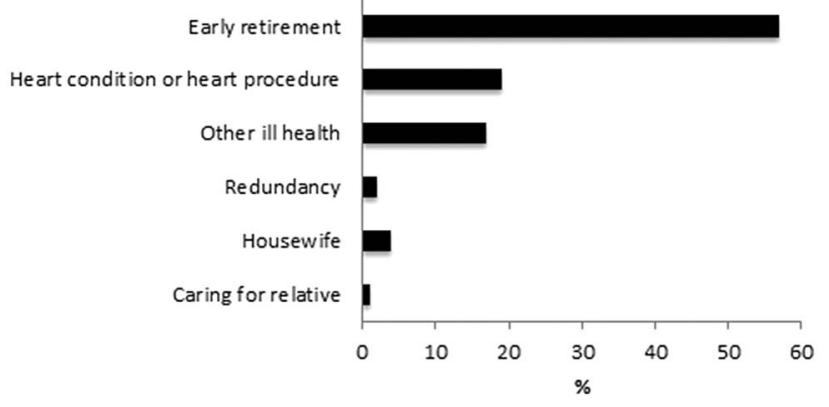

Figure 3 Reasons for unemployment post procedure. $\mathrm{CABG}$, coronary artery bypass grafting; $\mathrm{PCl}$, percutaneous coronary intervention. alone or acute procedure was associated with anxiety/ depression problems $(\mathrm{p}=0.035$ and $\mathrm{p}=0.015$, respectively); and those self-employed or with physical jobs had more usual activity problems $(\mathrm{p}=0.006$ and $\mathrm{p}=0.0002$, respectively).

Propensity analysis of a balanced cohort of 32 pairs likewise revealed no significant differences between PCI and CABG for self-reported health state scores ( $p=0.558)$ and for the five EQ-5D QoL domains: problems with pain/discomfort $(\mathrm{p}=0.794)$, anxiety/depression $(p=1.000)$, self-care $(p=0.321)$, usual activity $(\mathrm{p}=0.761)$ and mobility $(\mathrm{p}=0.755)$.

\section{DISCUSSION \\ Main findings}

Restoration of normal social-economic functional capacity, particularly RTW, is important but underresearched. The impact of revascularisation procedure on RTW and QoL, was the purpose of this study since all 
Table 3 Table comparing $\mathrm{PCl}$ and $\mathrm{CABG}$, with respect to return to work rates, employment $>12$ months postprocedure and time taken to return to work

\begin{tabular}{lllll}
\hline & CABG & PCI & $\begin{array}{l}\text { p Values from } \\
\text { multivariate analysis }\end{array}$ & $\begin{array}{l}\text { p Values from } \\
\text { propensity analysis }\end{array}$ \\
\hline $\begin{array}{l}\text { Employed preprocedure and returned to work, } \\
\text { N } \% \text { ) }\end{array}$ & $51(77)$ & $162(93)$ & 0.402 & 1.000 \\
$\begin{array}{l}\text { Employed preprocedure and still working } \\
>12 \text { months postprocedure, N (\%) }\end{array}$ & $41(62)$ & $147(85)$ & 0.165 & 0.756 \\
$\begin{array}{l}\text { Median time taken to return to work (weeks) } \\
\text { (range) }\end{array}$ & $13(2-52)$ & $6(0.14-78)$ & 0.001 & 0.001 \\
\hline CABG, coronary artery bypass grafting; PCl, percutaneous coronary intervention. & & \\
\hline
\end{tabular}

things being equal, socioeconomic factors could influence decision-making around choice of procedure.

Using data from a single high volume interventional and surgical centre, we documented RTW, long-term employment, time taken to RTW and QoL of patients undergoing either PCI or CABG procedures using DES, in the contemporary era. As might be expected recovery to enable work return was shorter after PCI, than after CABG, evidenced by earlier RTW, which can be considered socioeconomically beneficial. However, after propensity analysis there was no difference between contemporary PCI or CABG in overall RTW, long-term employment, or QoL, in this subset of patients. The propensity-score matching allows for potential confounding factors that may influence RTW and QoL postprocedure to be balanced between the two non-randomised cohorts. However, factors that may have had a bearing on the choice of revascularisation strategy (such as patient choice, complexity of coronary disease/ high SYNTAX score leading to CABG, or comorbidities that may result in higher surgical risk leading to complex PCI) cannot be accounted for using propensity matching. Hence, while this process would increase the robustness of any comparison between the PCI and CABG cohort, all of the confounding factors may not be fully accounted for between groups. Some of these factors may also impact on recovery postprocedure, or ability to RTW (eg, a residual ischaemic burden postrevascularisation may impact on ability to regain a group 2 licence). In this particular study, due to the differences in baseline factors, there was a reduction in the number of respondents following propensity matching, which in itself may limit detection of statistically significant differences in QoL or RTW parameters. However, if the propensity analysis holds then RTW and QoL should not drive decision-making regarding selection of a revascularisation procedure.

\section{Comparison with other studies}

Similar to previous studies, ${ }^{7}{ }^{14}$ we have confirmed that in the contemporary era patients RTW sooner after PCI than after CABG, but long-term employment is similar after the two procedures. Unlike some previous studies, ${ }^{15}$ which reported better long-term QoL after CABG than after PCI, we demonstrated no difference in QoL between the two procedures, in the contemporary

Table 4 Self-reported EQ-5D QoL scores for respondents treated with either CABG surgery or PCI, and who were employed preprocedure

\begin{tabular}{|c|c|c|c|c|}
\hline $\begin{array}{l}\text { Quality of life } \\
\text { domain }\end{array}$ & $\begin{array}{l}\text { CABG patients } \\
\text { employed preprocedure } \\
(n=66)\end{array}$ & $\begin{array}{l}\text { PCI patients employed } \\
\text { preprocedure } \\
(n=175)\end{array}$ & $\begin{array}{l}\text { p Values from } \\
\text { multivariate analysis }\end{array}$ & $\begin{array}{l}\text { p Values from } \\
\text { propensity analysis }\end{array}$ \\
\hline $\begin{array}{l}\text { Mobility problem, N } \\
(\%)\end{array}$ & $\begin{array}{l}12(18) \\
(5 \text { missing) }\end{array}$ & $\begin{array}{l}30(17) \\
(32 \text { missing) }\end{array}$ & 0.772 & 0.755 \\
\hline $\begin{array}{l}\text { Self-care problem, } \mathrm{N} \\
(\%)\end{array}$ & $\begin{array}{l}0 \\
\text { (5 missing) }\end{array}$ & $\begin{array}{l}6(3) \\
\text { (32 missing) }\end{array}$ & 0.261 & 0.321 \\
\hline $\begin{array}{l}\text { Usual activity } \\
\text { problem, N (\%) }\end{array}$ & $\begin{array}{l}18 \text { (27) } \\
(5 \text { missing })\end{array}$ & $\begin{array}{l}37(21) \\
\text { (32 missing) }\end{array}$ & 0.756 & 0.761 \\
\hline $\begin{array}{l}\text { Pain/discomfort } \\
\text { problem, N (\%) }\end{array}$ & $\begin{array}{l}25(38) \\
(5 \text { missing) }\end{array}$ & $\begin{array}{l}50(29) \\
(32 \text { missing) }\end{array}$ & 0.343 & 0.794 \\
\hline $\begin{array}{l}\text { Anxiety/depression } \\
\text { problem, N (\%) }\end{array}$ & $\begin{array}{l}13(20) \\
(5 \text { missing) }\end{array}$ & $\begin{array}{l}53(30) \\
(32 \text { missing) }\end{array}$ & 0.159 & 1.000 \\
\hline $\begin{array}{l}\text { Health state score } \\
\text { (median+range) }\end{array}$ & $\begin{array}{l}80(20-100) \\
(5 \text { missing })\end{array}$ & $\begin{array}{l}80(24-100) \\
(32 \text { missing) }\end{array}$ & 0.267 & 0.558 \\
\hline
\end{tabular}


era. Other studies have also reported no difference in QoL between PCI and CABG. ${ }^{16-19}$ Our findings are strengthened by the fact that we used propensity matching to minimise confounding.

Detectable variables associated with RTW after MVA were younger age, not having $\mathrm{DM}, \mathrm{EF}>30 \%$ and not being self-employed. Similarly, variables associated with long-term employment after MVA of the unmatched cohort, were younger age and not having DM. The former is to be expected, but the latter is interesting and requires some consideration. Longer-term complications of suboptimally controlled DM, such as retinopathy, neuropathy, renal impairment or peripheral vascular disease may be responsible for discontinued employment in the longer-term. However, this needs confirmation in prospective longitudinal studies of employment in patients with DM. Variables associated with worse selfreported health state scores after MVA of the unmatched cohort were living alone, DM, and having a physical job. The predictors of RTW and QoL outcomes that we observed were consistent with previous studies. In addition we have shown that DM may be an important determinate of functional status in this group.

The findings of this study may be considered intuitive. Timing of RTW after a medical procedure, is governed by many factors, including the intrinsic rate of physical recovery, for example, healing of a sternal incision, physician advice, employer policies, social factors and job characteristics. It is expected that the less invasive nature of PCI would enable more rapid convalescence and thus allows a patient to resume normal activities sooner than after CABG surgery. Nonetheless, from a patient perspective knowing that the median time taken to RTW after revascularisation may be at least twice as long after CABG surgery than after PCI (13 weeks vs 6 weeks, $\mathrm{p}=0.001$ ) may be important enough for the patient to be made aware of this prior to having a procedure.

\section{Limitations}

The findings need to be interpreted in light of the study limitations. First, the propensity matched cohort was small. However, the reason for this is that calipermatched propensity scores were used, ensuring patients were matched within one quarter of a SD for each criterion. This was necessary due to the highly disparate baseline characteristics of the PCI and CABG groups; the traditional 'nearest neighbour' method for propensity matching resulted in a larger but poorly-matched cohort from which it was difficult to draw conclusions. However, obtaining RTW data can be difficult even from clinical trial data, as excluding those patients who are likely retired ( $>65$ years of age) reduces the number of eligible participants. This in turn can affect the ability to detect differences between groups for some of the outcome measures, which may account for the disparity seen in longer-term QoL scores between our PCI/CABG propensity matched cohort and those reported in previous studies where propensity matching was not used. ${ }^{15}$
It is feasible that factor selection for the propensity analysis may mask differences and underestimate the less invasive nature of PCI. However, even when different combinations of variables were used to match the cohort for the propensity analysis, no differences in the main conclusions of this study were detected.

A potential limitation is that a large number of patients were excluded from the 2323 patients who had revascularisation procedures at the single centre between May 2012 and May 2013. This was necessary to address the aims of the study. Patients $>65$ years old were excluded due to possible work ineligibility and potential age-related functional status impairments. Patients who were unemployed preprocedure were logically excluded from the univariate analysis, MVA and propensity analysis, due to the fact that the main aim of the present study was to analyse RTW patterns.

The difference in proportions of missing QoL outcome data between PCI and CABG groups (table 4) may also potentially introduce bias, for example, the sickest patients may not have completed the QoL questionnaires. However, in a retrospective study such as this, questionnaires are often incompletely filled in by participants, thus this limitation cannot be circumvented fully.

\section{Conclusion}

This is the first propensity-matched study comparing RTW and QoL after PCI or CABG procedures. The results suggest younger age, not having DM, EF $>30 \%$ and not being self-employed are the strongest predictors of RTW. Contemporary PCI when compared to CABG, after propensity matching, appears to have no impact on RTW or QoL, in this subset of patients, although factor selection for the propensity analysis may mask differences and underestimate the less invasive nature of PCI. Irrespective, PCI patients RTW earlier than CABG patients.

Acknowledgements The authors thank Lorraine Shipley for her administrative assistance in mailing the questionnaires for this study.

Contributors AMM designed the return to work questionnaire, collected data, packaged the questionnaires for mailing, analysed the data, reviewed the literature and wrote the manuscript. JPH analysed the data. AHG conceived the idea for the project, and contributed to designing the return to work questionnaire. All authors edited the manuscript.

\section{Competing interests None declared.}

Ethics approval This study was deemed to be exempt from the requirement to obtain ethical approval by the Research Department of University Hospitals of Leicester NHS Trust.

Provenance and peer review Not commissioned; internally peer reviewed.

Data sharing statement No additional data are available.

Open Access This is an Open Access article distributed in accordance with the terms of the Creative Commons Attribution (CC BY 4.0) license, which permits others to distribute, remix, adapt and build upon this work, for commercial use, provided the original work is properly cited. See: http:// creativecommons.org/licenses/by/4.0/ 


\section{REFERENCES}

1. Leal J, Luengo-Fernandez R, Gray A, et al. Economic burden of cardiovascular diseases in the enlarged European Union. Eur Heart J 2006;27:1610-19.

2. McGee HM, Graham T, Crowe B, et al. Return to work following coronary artery bypass surgery or percutaneous transluminal coronary angioplasty. Eur Heart $J$ 1993;14:623-8.

3. Denvir MA, Lee AJ, Rysdale J, et al. Influence of socioeconomic status on clinical outcomes and quality of life after percutaneous coronary intervention. $J$ Epidemiol Community Health 2006;60:1085-8.

4. Isaaz K, Coudrot M, Sabry MH, et al. Return to work after acute ST-segment elevation myocardial infarction in the modern era of reperfusion by direct percutaneous coronary intervention. Arch Cardiovasc Dis 2010;103:310-16.

5. Fiabane E, Argentero P, Calsamiglia G, et al. Does job satisfaction predict early return to work after coronary angioplasty or cardiac surgery? Int Arch Environ Health 2013;86:561-9.

6. Niles NW II, Vandersalm TS, Cutler BS. Return to work after coronary artery bypass operation. J Thorac Cardiovasc Surg 1980;79:916-21.

7. Hlatky MA, Boothroyd D, Horine S, et al. Employment after coronary angioplasty or coronary bypass surgery in patients employed at the time of revascularisation. Ann Intern Med 1998;129:543-7.

8. Panasewicz A, Pedersen SS, Veenhuis JG. Health-related quality of life in the elderly three years after percutaneous coronary intervention. Eurolntervention 2013;9:373-81.

9. Spertus JA, Salisbury AC, Jones PG, et al. Predictors of quality-of-life benefit after percutaneous coronary intervention. Circulation 2004;110:3789-94.

10. Matty S. Predicting likelihood of long-term unemployment: the development of a UK jobseekers' classification instrument. Working paper No 116. Department for Work and Pensions, 2013.
11. EuroQoL Group. EuroQol-a new facility for the measurement of health-related quality of life. Health Policy 1990;16:199-208.

12. Package 'Matchlt'. 2015 (accessed: 18 May 2015). http://cran. rproject.org/web/packages/Matchlt/Matchlt.pdf

13. Package 'Zelig'. 2015 (accessed: 18 May 2015). http://cran.r-project. org/web/packages/Zelig/Zelig.pdf

14. Allen JK, Fitzgerald ST, Swank RT, et al. Functional status after coronary artery bypass grafting and percutaneous transluminal coronary angioplasty. Am J Cardiol 1990;66:921-5.

15. Borkon AM, Muehlebach GF, House J, et al. A comparison of the recovery of health status after percutaneous coronary intervention and coronary artery bypass. Ann Thorac Surg 2002;74:1526-30; discussion 1530.

16. Hlatky MA, Boothroyd DB, Melsop KA et al. Medical Costs and quality of life 10 to 12 years after randomisation to angioplasty or bypass surgery for multivessel coronary artery disease. Circulation 2004;110:1960-6.

17. Abdallah MS, Wang K, Magnuson EA, et al., FREEDOM Trial Investigators. Quality of life after PCl vs CABG among patients with diabetes and multivessel coronary artery disease: a randomized clinical trial. JAMA 2013;310:1581-90.

18. Rumsfeld JS, Magid DJ, Plomondon ME, et al., Department of Veterans Affairs Angina With Extremely Serious Operative Mortality (AWESOME) Investigators. Health-related quality of life after percutaneous coronary intervention versus coronary bypass surgery in high-risk patients with medically refractory ischemia. J Am Coll Cardiol 2003;41:1732-8.

19. Wahrborg P. Quality of life after coronary angioplasty or bypass surgery 1-year follow-up in the Coronary Angioplasty versus Bypass Revascularization Investigation (CABRI) trial. Eur Heart $J$ 1999;20:653-8. 